\title{
Id@rt Experience: A Transnational Blended- learning Project Founded on Visual Culture
}

\author{
http://dx.doi.org/10.3991/ijet.v10i2.4283 \\ Alice Bajardi ${ }^{1}$, Serena Giulia Della Porta ${ }^{2}$, Dolores Álvarez-Rodríguez ${ }^{1}$, Cristina Francucci ${ }^{3}$ \\ ${ }^{1}$ Granada University, Granada, Spain \\ ${ }^{2}$ MAMbo Museum, Bologna, Italy \\ ${ }^{3}$ Bologna Fine Arts Academy, Bologna, Italy
}

\begin{abstract}
This article is the result of interchanging experiences, the Id@rt experience, among artists, educators and students from different countries and contexts that share the concept of identity as a subject matter for the artistic and educational research processes. We followed a methodological framework that combines the visual culture art education, as an approach to make and interpret the visual reality, and the blended-learning, as a tool to transform and improve the learning process. We proposed the Id@rt experience to teacher in training at the Granada University (Spain), and to student of communication and art education course at the Bologna Fine Arts Academy (Italy). The aim of this project is to develop a closer look at contemporary art, promote creativity and foster the social skills promoting new ways of communication and creation. Through this project we propose to create a synergy between the use of traditional art education methods and the new-technologies based-methods (ICT and e-learning). The evaluation results of the Id@rt experience, obtained from our observation together with focus-groups and open-end questionnaires, indicate that the participants increased their creativity and developed their social/communicative competencies, experiencing art and new technology languages and discovering the creative identity of the contemporary artist and of themselves. Projects like Id@rt experience pave the way for a new understanding and teaching of the art education and new interpretations of the contemporary art and the visual culture.
\end{abstract}

Index Terms-ICT in Art Education, Teacher training, Blended Learning.

\section{INTRODUCTION}

The information and communication technology (ICT) and the visual culture are two important elements of the social life that influence and form the professional and personal identity. For this reason these elements should be taken into consideration both in the school curriculum and teacher training. Although the art education discipline is slowly introducing various experience based on ICT (e.g. forums, web pages, social networks, databases, multimedia projects connecting various educational environments), there is a reluctance to develop e-learning paths compared to other disciplines [1-3]. We observed that in the field of art education, especially in the Italian and Spanish educational institutions such as museums, universities and schools, a dichotomy is still present. Indeed, there is a part of art educators who defend the tradition with its methodologies and tools, in contrast to others that consider the use of technological tools and e-learning methodology as a viable and positive alternative to tradi- tional educational models, because they improve communication skills and increases the motivation to learn and participate directly in the knowledge construction [4]. Among teachers who do not integrate new technologies into their art education programs there are some of them, who are interested and are motivated to use new technologies and methodologies, but they do not feel adequately trained, or their centres are not equipped with suitable resources. Other art educators categorically reject the use of new technologies and methodologies because they believe that the use of fine arts traditional tools and methodologies are more appropriate to stimulate students' creativity and they consider that face-to-face practice experience promotes the development of important socioemotional skills [5]. We consider that these two methods should not be considered as opposite and exclusive, but there is a possibility that these methods could be integrated because they share many common goals. In order to explore the efficiency and validity of this integration, we carried out a research consisting of the creation and presentation of an educational proposal together with the interpretation of associate results that we present in this paper. This educational proposal was named Id@rt experience merging the key themes of the project that are the identity, the use of the Internet and new technologies, the art and the experience. Id@rt experience has been submitted to Spanish teachers in training and Italian fine arts students and consists of an art education e-learning project that uses an on-line platform but provides a practical, faceto-face aesthetic experience as well.

\section{MethodOLOGY}

The research methodology applied in the Id@rt experience is based on visual culture art education and blendedlearning (b-learning) applied to the art teaching as a new way of learning and knowing. Visual culture art education is a critical and qualitative interpretive-approach that includes the use of all forms of audio-visual culture in the classroom [e.g. 6, 7]. Thus, this approach does not use or consider only 'greatest works of art' but include what is broadly understood as visual culture $[6,8]$. Furthermore, the visual cultural educative experiences are considered highly useful for the self-reflection and expression provided to users and for the exploration and construction of their identity, which is understood not as a static element but as something in constant evolution and in relation to external environment $[2,7]$. The blended-learning used in our educational methodology typically combines the traditional face to face lesson (in our case in the field of art education), and e-learning consisting of communication, 
PAPER

ID@RT ExPERIEnce: A Transnational Blended-LEARning Project Founded on Visual Culture

information and training activities mediated by computer or mobile systems [9]. In fact, the key element of Id@rt experience methodology is the continuous passage and exchange of aesthetic experiences in different work environments, from the virtual to real and conversely, combining the advantages of direct experience and new technologies.

The educational methodology adopted in the Id@rt experience is based on constructivism that gives the student a central role as a constructor of knowledge and learning, meanwhile the teacher play a role as facilitator and guide to achieve a critical understanding through experiences based on arts and the use of ICT [4, 10-11]. We selected this methodology because we do not conceive the teacher as the only possessor of knowledge, and we think that the student is more that a consumer of knowledge receptive to the teacher's implied power, considering, moreover, that the arts learning is an active process and the meaning is developed from experience [12-14]. For this reason, we consider that this constructivist theory of learning offers the best approach to visual culture learning environments and for integrating ICT in art education and training. In order to evaluate the project, be aware of its strengths and to improve its weaknesses in future applications we collected feedback and opinions from users using the following evaluation methods: observation, focus groups, and open-ended questions.

\section{A MULTIMEDIA PROJECT ON IDENTITY IN CONTEMPORARY ART}

The Id@rt experience, our educational proposal, is part of the Identikit subproject, which is the fourth stage of Didart project financed as the best proposal for communication and contemporary art education, by the European Commission, in the Visual Arts category of the Culture Program. Didart provided a multilingual and transnational platform on contemporary art education, which was conceived by Cristina Francucci, with the editorial coordination of Anna Caratini and the design and production of Chialab Srl. Identikit is a multimedia project on identity in the contemporary art field that has been proposed in various educational settings such as museums, universities, schools and foundations including: MAMbo - Museum of Modern Art (the lead institution of the project), Fine Arts Academy and Giannino Stoppani Cultural Cooperative (Bologna), Civic Museums (Reggio Emilia), some public schools of Emilia Romagna, Educational Sciences Faculty of Granada, Fine Arts Faculty of Barcelona, Azienda Speciale Palaexpo, Palazzo delle Esposizioni and Scuderie del Quirinale (Rome), Louisiana Museum of Modern Art (Copenhagen), Museum Ludwig (Cologne), Foundation of Contemporary Art (Bratislava) and Zeeuws Museum (Middelburg).

The Id@rt experience was proposed as a b-learning path, which we named "experiential e-learning path", where workshop proposals and the knowledge of the artists' poetics are individually discovered by the user through computer in their own spare time. With Id@rt experience we want to give importance to the experience, the act of "doing" (an element that is not always present in online educational proposals) as a key for the understanding of contemporary art. In fact, in this educational project, the encounter with art does not occur through transmission of information or critical text reading, but the three aforementioned contemporary artists offer to the user some useful experience to understand their poetics [15-16]. The role of the educator in id@rt experience, which coincides with the researcher, is not to convert all individuals in artists, but bring them closer to the language of the arts, and propose methods and guide to independent use of digital tools that can be used for learning, teaching and research [2, 17-18].

The Id@rt experience educational path, in particular, was designed to introduce secondary schools and universities students to the poetics and identity of three contemporary artists: Massimo Bartolini, Eva Marisaldi and Alessandra Tesi. We encouraged the users to make a personal processing of creative stimuli suggested by these three artists through the Didart platform.

The Didart online profiles of these artists have the same scheme in order to facilitate access and interactivity. This scheme includes the biographies of the three contemporary artists, a selection of their main artworks, and, finally, their proposals, namely four practical exercises of audiovisual culture education to be proposed to users.

\section{A. The Id@rt experience contents and objectives}

The overall objective of this project was to create in the art education a relationship between online learning, in which each user can access freely, with the experience to live in not digital reality. Meanwhile, the specific objectives of the proposal were: to suggest visual-culture-based and ICT methodologies and tools to teachers in training, to bring students closer to the art world by living a direct approach to contemporary art poetics and to create links between students, educators and artists coming from different countries and contexts, using new technologies / blearning and living common experiences based on identity artistic research.

In practice, the Id@experience digital platform allowed users to sign up, to become part of a virtual classroom, and to access to the profiles and activities proposed by the three contemporary artists involved. All contents of the online platform were in Italian and English, and later were translated into Spanish by Alice Bajardi for Granada University users. In the Id@experience each artists followed the sequence below to present their poetics and creative identity and later the educational activities useful to its understanding.

1. The three artists, using images and/or words, choose a way to introduce their creative identity.

2. The artists selected three of their most significant artworks and present them to users by using images and text.

3. The first experience consists in the presentation to users of one or more audio-visual culture items (e.g. a film, a literature piece, a video, a song, an image) that the artists consider essential for their own artistic culture development. The users are required to give a feedback consisting in a reflection on the enjoyed artistic experience

4. The second experience is developed through an educational proposal by the artist, so that their poetics can be understood. Finally, the users are required to document the proposed experience.

5. In the third experience the users are request to produce or rework an artifact as result (a significant action) of the artist-poetics understanding-process. The production of the artifact has to be documented. 
PAPER

ID@RT ExPERIEnce: A Transnational Blended-LEARning Project Founded on Visual Culture

6. In the fourth experience the users are invited to place their work in a physical or virtual environment and to document and justify their choice.

\section{RESULTS: SPANISH AND ITALIAN ID@RT EXPERIENCES}

In this section we present the results obtained from the Art Education and Communication students of Fine Arts Bologna Academy and the teachers in initial training of the Granada University Education Faculty, describing first the similarities and then the differences between the Spanish and Italian experiences. As first result, the Id@rt experience has been developed in all its parts, creating both phases of collective involvement and individual research times, allowing respectively to carry out an artistic research based on past experiences and new Id@rt experience incentives, and to share ideas that have been enriched thanks to the contributions of other users.

The experimentation of the project was carried out for about two months by classroom and virtual meetings. All students became members of the virtual classroom by registering on the website Didart in the Identikit. Then, among the different paths of the three contemporary artists contained in the Id@rt experience, we selected the path proposed by Alessandra Tesi that is an artist who lives and works in France. This artist uses photography and video installations to study and experiment the light including the colour-temperature and the effects on different materials (figure 1). Thus, we selected the Alessandra Tesis's path because the diversified arteducation proposals and the variety of audio-visual culture suggestions that she provides allow engaging a heterogeneous public and providing to users the opportunity to deal with a wide range of topics.

In the first experience of this educational path, the users virtually met Alessandra Tesi by her presentation consisting in "the colour story", which resulted particularly suggestive and effective because allowed the users to enter in empathy with the artist and to come closer to her poetic. Moreover, the users downloaded from the platform different types of contents recommended by the artist, such as video, music and texts organized according to five topics: the repetition, the detail, the transparency, the isolation and the transformation. The aim of this activity was to understand her artistic research and to offer the chance to experience contemporary art languages and contents. Indeed, the users have to personally and creatively elaborate these contents and finally created three images and a sentence to upload in Didart platform. Approximately half of the users personally took photos, while the other half extrapolated and interpreted visual culture images acquired form Internet. Furthermore, the users accompanied their images by a brief personal text or an extract from literature, in general no longer than five lines and adopting a poetic-polysemic style, and a descriptive-expressive style as well. During this first phase, the users encountered difficulties uploading the results of their experiences, because the platform allow upload pictures and videos only in specific formats. Thus, our role as tutors was to mediate between the users, the Didart platform and webmasters to make more fluid the subsequent operations.
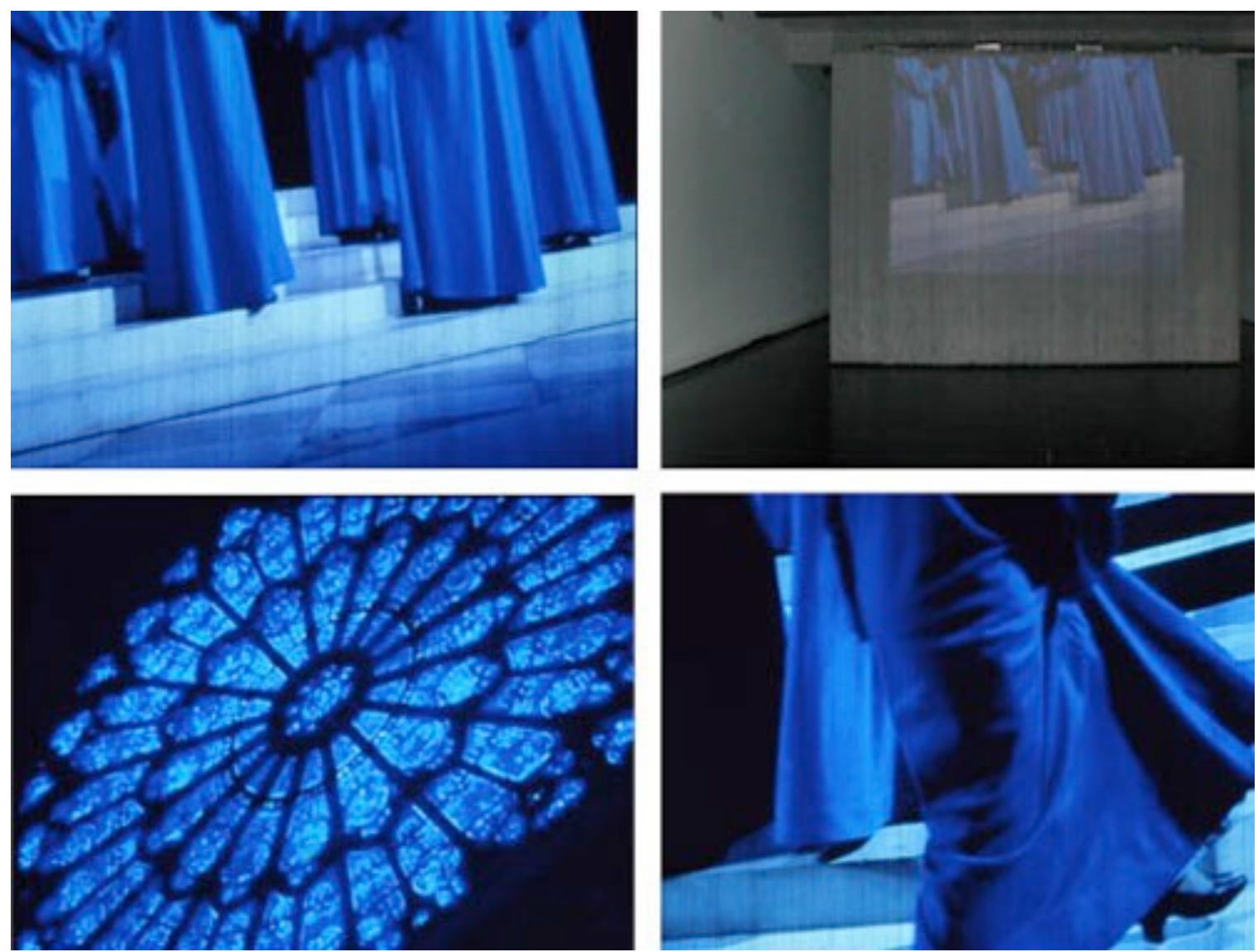

Figure 1. Alessandra Tesi (2002), Cattedrale. Videoinstallation (audio and video projection on glass beads mounted on wires, $\mathrm{cm} 500 \times 280$ ) 
PAPER

ID@RT EXPERIENCE: A TRANSNATIONAL BLENDED-LEARNING PROJECT Founded on VisuAl CULTURE

The Spanish users group (teachers in initial training) worked mainly on the stimuli that the artist gave about colors (blue, red, green, silver, gold and black), meanwhile most of the Italian students worked on the concept of isolation that has been proposed in reference to a place, a state of mind, a physical condition or an action carried out in solitude. In both case, this activity was carried out by watching three films suggested by the artist, "Barton Fink" by Joel and Ethan Coen [19], "The Shining" by Stanley Kubrick [20] and "Call Northside 777" by Henry Hathaway [21], the reading of an extract of "Les enfants terribles" by Jean Cocteau [22] and the observation of the "Couvent de la Tourette" architecture by Le Corbusier [23].

The Italian users group (university students) employed several hours watching movies followed by group reflection times to understand the influences that form the basis of the A. Tesi's artistic research. This experience became a "cineforum", a film discussion group aimed to track down all the important issues for the artist in the film and to acquire other points of view, which we consider as an active participation time and an effective approach to understand the creative process. The Spanish group, instead, decided to see only some clips of the films suggested by the artist and to recite some verses in class, but we suggested to the users by watching at home, in their spare time, some of those movies in full.

The second experience consisted in the investigation of the space taking as references the Alessandra Tesi's method used for the realization of some of her work on crime scenes and the "tunnel look". The artist invited the users to see the F. Ford Coppola's film "The Conversation" [24] and then proceed to the recording of a space by audio and video, in accordance with the following guidelines:

1. To observe the space from a 360 degrees point of view;

2. To proceed by details;

3. To remember the importance of missing parts.

The challenge for the participants was to present their idea in a video no longer than two minutes, with limited tools and knowledge. The results of this experience obtained from both Italian and Spanish groups were focused on a common field of research, in fact all the videos narrated various aspects of daily life, ordinary gestures or every day and mechanically lived places but recorded with a new look, as if it was lived for the first time.
For the third experience, called "the pencil", Alessandra Tesi asked users to carry out an infinite image or sound, like a big collage or a sound editor. To do this, the artist advised the students to bring with them always a tool (a pencil, a camera, etc), thus having a medium between them and reality that could encouraged them to use it for the watching process. The Spanish users group, after some individual artistic research carried out, decided to make one large and collective poster formed by a mix of visual techniques that put in connection all individual artistic outcomes. Instead, the Italian students' outcomes of this experience were individual and very diversified. In addition, the projects diversity has been emphasized by the use of different art tools and techniques, in fact endless audiovisual strips were made by editing audio and video, drawings, painting, collage, text and photographic sequences (figure 2).

During the fourth experience the user is required to place in a space the work developed during the second and the third experience. Thus, the artist leads on the users to experience a fantastic journey through imaginative visions, and she describes this experience as follows:

- To imagine a place;

- To plan, design and install in the space;

- To visualize the biggest dream, the loss of size, the flying house, the loss of gravity, the glass palace, the Wizard of $\mathrm{Oz}$.

Alessandra Tesi gave the users freedom to choose the ideal place to locate their infinite poster making references to the imaginary space of the film The Wizard of Oz [25]. The Spanish group opted to install its long poster in the Faculty hallway. In addition, they placed on the walls a selection of photographs of Id@rt experiences, inaugurating an exhibition that remained open for several weeks. Then, they divided the long poster in six parts and each part was given to a group of five students. They created five artist's books by reusing and reinterpreting the pieces taken from the exposed poster working on content, colors, shape, composition and rebinding.

The Italian students experienced solutions available for their works in outdoor environments, in a private room, in silent abandoned houses or in a taut string suspended in the air (figure 3 ). All the proposed solutions were accompanied by written reasons and resulted consistent with the other experiences and the aesthetic choices made during the entire b-learning path.

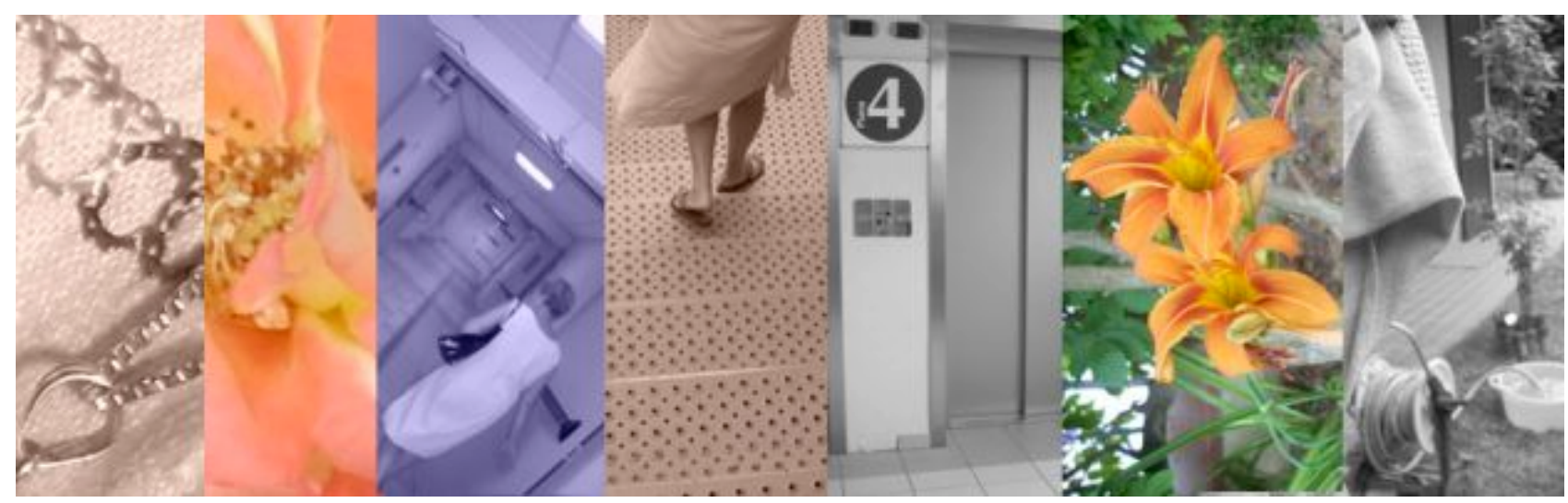

Figure 2. Inspired by a day spent in hospital. Photographic sequence of an Italian Id@rt experience student. 
PAPER

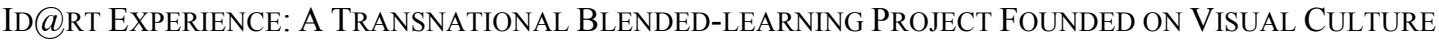

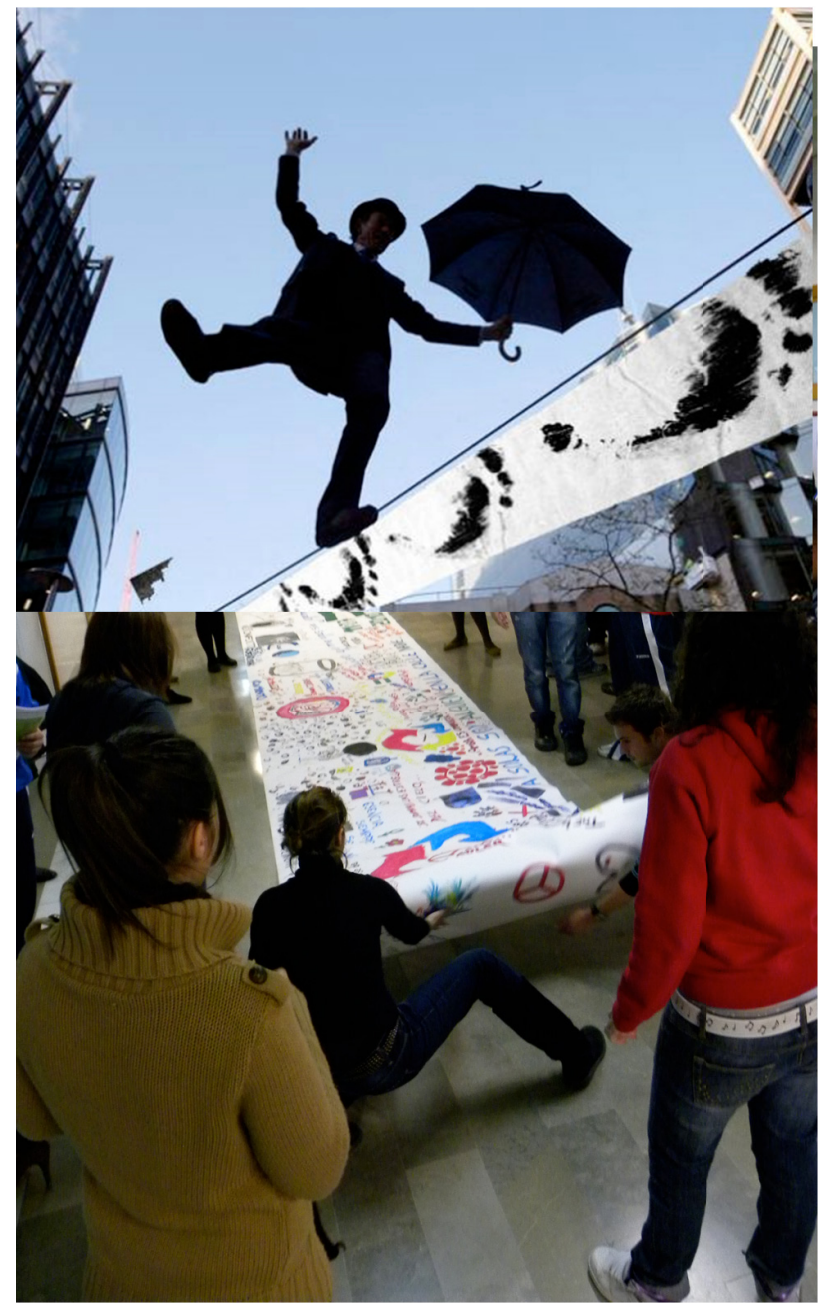

Figure 3. Alice Bajardi (2014) The meeting of two lines extended to infinity. Photo Series consisting of a photo taken by a student of Italian Id@rt experience group (top), and a photo by a member of Spanish Id@rt experience group (down).

To complete the Id@rt experience, both the Italian students and the Spanish teachers in training were encouraged to compose an essay in order to remind the work steps and their motivations. We evaluated the project through ongoing observation, focus groups and an openend questionnaire. In the questionnaire, we invited users to reflect on the physical, social and intellectual Didart accessibility and to write their opinion on the project objectives. Moreover, we asked them to give their impression on the organization of Didart platform and possible elements to add or remove from the project. To analyze the learning, teaching and research aspects, we asked user opinions and suggestions on teaching and learning provided through this project. In addition, we asked to specify whether and which innovations this project brought, and we invited participants to reflect on the use of new methodologies in art education. Finally, we asked users to write what Id@rt experience provided them about aesthetic and emotional aspects (aesthetic pleasure, internal-external pleasures, emotions, feelings and the level of calm or unrest). By this questionnaire, we wanted to know if the project was interesting for the participants (and the reasons) and if they would have wanted to develop a part of the project, specifying which part and in what manner they would have developed it.
Summarizing the results of the assessment questionnaires, the users considered the Didart platform easily accessible, despite the initial difficulties, but not completely open to the public because the restricted access to educational proposals by a classroom password given by the tutor. About the suggestions received to improve Id@rt experience, some participants proposed to add experience proposals for work not only with visual but also plastic materials, demanding more references and practical activities related with the sculpture. The users have also considered Id@rt experience an innovative project, in particular for the use of the digital platform to make art education in a different way and for the new proposed forms to exhibit their artworks (figure 3). The participants showed great enthusiasm on the learning and teaching aspects, believing that Id@rt experience is a project that stimulates creativity, imagination, understanding and interpretation of visual language, empathy, communication and socialization. Finally, about the aesthetic and emotional aspects, the users made reference to the perception of a very colorful environment, the gaiety, the feeling of freedom, relaxation, tranquillity, and the curiosity and happiness of approaching something original. In detail, the Spanish group considered interesting the ideas suggested by their tutor to create in group a collective creative communication, coinciding with the realization of the long-poster, and to transform a finished artwork, consisting in the transformation of the long poster into artist' books.

\section{DISCUSSIONS}

The personal and professional identities, as well as the education, are processes of life that change and grow continuously through the interaction between new and past experiences [2]. We have tried to stimulate this interaction by proposing to future art educators the Id@rt experience project, as a b-learning model based on visual culture experiences in order to promote contemporary art and ICT as new ways of teaching, learning and research. In fact, the Id@rt experience project uses the online technology not exclusively as a supplement, but as a tool to transform and improve the learning process [26]. Furthermore, this methodology allowed us to come into direct contact with the artists from other countries, to share creative materials and to exchange information quickly and effectively between the different player of the project, the students, the educators and the artists.

In detail, the structure of the e-learning platform Didart allowed users to easily get in contact with the Alessandra Tesi's poetics and the creative process guided directly by the artist. The variety of information and the pluridisciplinary approach involved the users to achieve and share research experiences similar to those of the artist. In addition, this learning system responds adequately to the needs of the contemporary art education. In fact, the contemporary artwork has often an ambiguous and open nature that feeds on the interaction and the active participation of the public. Teachers usually play the role of intermediary between the artist/artwork and the public/students to facilitate this active participation. However, in our project the artist acts directly as an intermediary between her artwork and the public, while the educator facilitates, guides and interprets the learning process involved. In addition, Id@rt experience pluridisciplinary structure promotes the character of the artwork as a bridge between 
PAPER

ID@RT ExPERIEnce: A Transnational Blended-LEARning Project Founded on Visual Culture

the personal reality of the artist and external reality, as "window open to the world", an idea that was conceived for first time by Leon Battista Alberti during the Renaissance [27].

Looking at the project results obtained, the realization of the collective long poster developed socio-emotional skills of the Spanish Id@rt experience group. In fact, the results of the evaluation questionnaires underline that this activity represented a time of merriment and socializing that motivated users to communicate among them and to find points of agreement. In addition, the exhibition of poster valorised the work done, allowed participants to see with new viewpoints, encouraged the exchange of views and publicized the project. On the other hand, we consider that the following decomposition of the poster by giving it new meanings, forms and contexts, through the creation of various artists' books had allowed avoiding the artwork mystification and the consequent stereotypes creation. During these project phases (the third and the fourth experience), the Italian Id@rt experience group worked individually going deeper into the personal artistic research by producing their own elaborated artistic results but, at the same time, it did not allowed building a collective creative identity. However, this group developed social competences, overall the horizontal relationship feature [28], during the first experience by the exchange of views and the group interaction for common research purposes (above all during the "cineforum" activity).

About the competencies acquired by the users, the Id@rt experience allowed developing personal and professional basic competencies such as the communicative skill, the autonomy, the personal initiative, the critical and reflective thinking. A clear example of this development were the blogs that some participants voluntarily created and used as diaries to tell, interpret and reflect (by texts and audiovisual material) on the experiences generated by this project. Furthermore, this example shows a significant increment of the users' motivation into the contemporary art learning and the related method that we used. The motivation increment is further supported by the evaluation results obtained by observation, questionnaire and focus group that showed enthusiasm and willingness to readopt this learning method that has been considered by the users challenging and effective. Thus, art education projects likeId@rt experience pave the way for a new understanding and teaching of the art education and new interpretations of the contemporary art and the visual culture in general.

\section{CONCLUSIONS}

The Id@rt experience, as b-learning project/path based on visual-culture art education, promoted the use of both traditional art education methods and the newtechnologies based-methods (ICT and e-learning) providing the synergy and integration of these two different methods that are normally used as exclusive. Such a synergy has been efficiently implemented by practical activities and on-line proposals and, at the same time, both users' evaluations and our observation shown that this integration has been efficient with regard to motivate students and to bring them closer to the contemporary art poetics and languages as well as to promote their basic personal and professional competencies. Furthermore, this project opens the way to new art-education potentialities that comes out from museum, schools and universities to enter into the homes of all those who use the Internet and at the same time it promotes to involve different disciplines and professional identities as artists, educators, technicians and students.

About the benefits that received the users of the project, the use of the on-line platform together with the practical artistic experiences allowed and promoted the direct approach to the contemporary art understanding. Starting from the researches and the methodologies emerged in the field of "contemporary fruition" [27], we believe that the experimental approach of Id@rt experience promotes a bond between artist and public that leads the user to do a creative process similar to the artist one, acquiring critical awareness in the development of their artistic research. At the same time, using the b-learning we attempted to avoid/solve some virtual issues, such as exclusion from reality and the reduction of human relations. Id@rt experience developed the social skills of the participants, as socialization and cooperative spirit, by experimenting possibilities and solving difficulties both in the use of the digital platform and in the creative activities based on artistic disciplines and visual culture. Furthermore, this experience promoted new and different ways of communication and expression, as well as the awareness, the experimentation, the imagination, and the creativity as confirmed by the evaluation results obtained from the observation, the focus groups and the questionnaires. Finally, users were positively impressed by this approach to the contemporary art poetics and languages, both personally and professionally, and they communicated (orally and in writing) their intention to continue to develop this area of interest and to propose visual-culture art education projects likeId@rt experience to their future students.

\section{ACKNOWLEDGMENT}

We would like to thank the Department of Didactics of Musical, Plastic, and Corporal Expression of the Granada University and the Educational Department of the Mambo Museum of Bologna. We especially thank Tarynne Swarts and Flavio Giaconia, researchers of the Granada University, for their linguistic and technical revisions.

\section{REFERENCES}

[1] R. A. Gómez, "Aplicaciones Web 2.0 como recursos didácticos interactivos en los estudios de Bellas Artes," RELADA-Revista Electrónica de ADA-Madrid, vol. 4, 2010.

[2] A. Bajardi and D. Álvarez-Rodríguez, "Contribuciones de la educación artística a la construcción de la identidad profesional docente: competencias básicas y comunicativas," Historia y Comunicación Social, vol. 18, pp. 615-626, 2014. http://dx.doi.org/10.5209/rev_HICS.2013.v18.44266

[3] D. Álvarez-Rodríguez, "Blended Learning in Art Education: New ways of improving visual literacy," in International Dialogues About Visual Culture, Education and Art., R. Mason and T. Torres Pereira de EÇA, Eds., ed Bristol, UK / Chicago, USA: Intellect, 2008, pp. 121-129.

[4] D. Di Marco, et al., "Contenuti e creatività nel web 2.0 e nel mondo virtuale: il progetto ST. ART," presented at the DIDAMATICA 2011, Torino, 2011.

[5] G. Manca, "Contributi dell'arte alla formazione della persona: alcune considerazioni pedagogico-didattiche," in Itinera: studi in memoria di Enzo Cadoni, M. Francesco Gesuino, Ed., ed Sassari: EDES Editrice Democratica Sarda (stampa Tipografia TAS), 2000, pp. 315-328.

[6] P. Duncum, "Clarifying visual culture art education," Art Education, vol. 55, pp. 6-11, 2002. http://dx.doi.org/10.2307/ 3193995 
PAPER

ID@RT ExPERIEnce: A Transnational Blended-LEARning Project Founded on Visual Culture

[7] K. Freedman, "The importance of student artistic production to teaching visual culture," Art Education, vol. 46, pp. 38-43, 2003.

[8] K. Tavin, "Hauntological shifts: Fear and loathing of popular (visual) culture," Studies in Art Education, vol. 46, pp. 101-117, 2005.

[9] J. Bele and J. Rugelj, "Blended learning - an opportunity to take the best of both worlds," International Journal of Emerging Technologies in Learning (iJET), vol. 2, 2007.

[10] B. G. Wilson, Constructivist learning environments: Case studies in instructional design. Englewood Cliffs: Educational Technology, 1996.

[11] J. Simpson, "Constructivism and Connection Making in Art Education," Art Education, vol. 49, pp. 53-59, 1996. http://dx.doi.org/10.2307/3193579

[12] J. Katz-Buonincontro, "Decorative Integration or Relevant Learning? A Literature Review of Studio Arts-Based Management Education With Recommendations for Teaching and Research," Journal of Management Education, November 6, 20142014. http://dx.doi.org/10.1177/1052562914555192

[13] B. P. Woolf, Building intelligent interactive tutors: Studentcentered strategies for revolutionizing e-learning. Burlington: Morgan Kaufmann, 2010.

[14] M. D. Merrill, "Constructivism and Instructional Design," Educational Technology, vol. 31, pp. 45-53, 1991.

[15] M. Dallari and C. Francucci, L'esperienza pedagogica dell'arte. Firenze: La Nuova Italia, 1998.

[16] C. Francucci and P. Vassalli, Educare all'arte. Milano: Electa, 2005.

[17] M. Cebrián de la Serna, "Los centros educativos en la sociedad de la información y el conocimiento," in Procesos educativos con TIC en la sociedad del conocimiento, M. a. G. A. Cebrián de la Serna, M.J., Ed., ed Madrid: Pirámide, 2011, pp. 23-31.

[18] H. Read, Education through art: Faber \& Faber London, 1958.

[19] J. Coen and E. Coen, "Barton Fink," ed. United States: 20th Century Fox, 1991.

[20] S. Kubrick, "The shining," ed. United States: Warner Bros, 1980.

[21] H. Hathaway, "Call Northside 777," ed. United States: Twentieth Century-Fox Film Corporation, 1948.

[22] J. Cocteau, Les enfants terribles (I ragazzi terribili): Rizzoli, 1998.

[23] L. Corbusier, "Convent Sainte-Marie de La Tourette," ed. Éveux, 1960 .
[24] F. Ford Coppola, "The Conversation," Chew, Richard Murch, Walter ed. United States: Paramount Pictures, 1974.

[25] V. Fleming, "The Wizard of Oz ", ed. United States: MetroGoldwyn-Mayer, 1939.

[26] A. G. Picciano, et al., Blended Learning: Research Perspectives vol. 2: Routledge, 2013.

[27] V. I. Stoichiță, L'invenzione del quadro. Arte, artefici e artifici nella pittura europea. Milano: Il saggiatore, 1998.

[28] L. Rose-Krasnor, "The nature of social competence: A theoretical review," Social development, vol. 6, pp. 111-135, 1997. http://dx.doi.org/10.1111/j.1467-9507.1997.tb00097.x

\section{AUTHORS}

Alice BAJARDI is with the Department of Didactics of Musical, Plastic, and Corporal Expression of the Granada University, Granada, Campus de Cartuja s/n 18071 SPAIN (e-mail: alicebajardi@gmail.com).

Giulia Serena DELLA PORTA works, through Senza Titolo Cultural Association, at Bologna Modern Art Museum, MAMbo, Via Don Minzoni 14, Bologna, 40121 ITALY, (e-mail: serenadellaporta@gmail.com).

Dolores ÁLVAREZ-RODRIGUEZ is the Department of Didactics of Musical, Plastic, and Corporal Expression Director, Granada University, Granada, Campus de Cartuja s/n 18071 SPAIN (e-mail: alvarezr@ugr.es).

Cristina FRANCUCCI was the Education Department Coordinator of the Bologna Modern Art Museum, MAMbo, Via Don Minzoni 14, Bologna, 40121 ITALY. She is now director of the Department of Communication and Art Education at the Bologna Fine Arts Academy, Via Belle Arti 54, Bologna, 40126 ITALY (e-mail: cristina.francucci@gmail.com).

This research has been possible thanks to a Granada University Scholarship. Furthermore, this work was supported by a funding for Basic Research un-oriented Projects (2012) of the Economy and Competitiveness Ministry of the Spain Government, reference: HAR2012-35050 (2013-2015). Submitted 17 December 2014. Published as resubmitted by the authors 24 March 2015. 